\title{
Expiration Date Production Identifier
}

National Cancer Institute

\section{Source}

National Cancer Institute. Expiration Date Production Identifier. NCI Thesaurus. Code C101670.

The production identifier is the expiration date. 